\title{
Gas Scavenging Device
}

National Cancer Institute

\section{Source}

National Cancer Institute. Gas Scavenging Device. NCI Thesaurus. Code C49967.

A device designed to remove certain gases from a gas stream or environment. 